\title{
KARAKTERISASI ABU SEKAM PADI DISINTESIS POLIETILEN GLIKOL- 6000 SEBAGAI BAHAN PENGISI NANO KOMPOSIT TERMOPLASTIK HDPE
}

\author{
Eva Marlina Gintinga), Karya Sinulingga, Mukti Hamzah Harahap, \\ Martha M Padang, Nurdin Bukit ${ }^{\text {b) }}$ \\ Prodi Fisika FMIPA Universitas Negeri Medan 20211 \\ E-mail: a)evamarlina67@yahoo.com, b) nurdinbukit5@gmail.com
}

\begin{abstract}
Abstrak
Tujuan penelitian ini adalah pembuatan nano partikel dari abu sekam padi (ASP) yang berfungsi sebagai sebagai bahan pengisi termopastik high density poliethylen (HDPE). ASP yang akan dipreparasi diperoleh dari Kilang Padi hasil pembakaran yang berwarna putih . Dalam penelitian ini metode yang dilakukan dalam pembuatan nano partikel dengan cara ASP di Ball mill selama 1 jam kemudian di sintesis dengan larutan $\mathrm{HCl} 2 \mathrm{M}, \mathrm{NaOH} 2.5 \mathrm{M}$ dengan metoda kopresipitasi dan di sintesis dengan polietilen Glikol ( PEG) 6000 dengan perbandingan 1:3 .Hasil ASP ini di karakterisasi yakni dengan alat X-Ray Floresensi (XRF), analisa morfologi dengan Scaning Electron Microscofe (SEM), analisa struktur X-Ray Difraction (XRD), Untuk membuat nano komposit maka dilakukan tahap sebagai berikut : termoplastik HDPE dimasukkan dalam internal mixer laboplastomill dengan suhu $150{ }^{\circ} \mathrm{C}$ dengan laju $60 \mathrm{rpm}$ selama 10 menit, nano ASP dengan hasil sistesis pada komposisi $(0,2,4,6,8$,dan 10$) \%$ berat . Dari hasil nano komposit dianalisis sifat mekanik ( kekuatan tarik , perpanjangan putus dan modulus elastik ) . Hasil yang diperoleh dengan XRD ukuran partikel 52,22 nm dan struktur kristal tetragonal dan fase kristobalit $\left(\mathrm{SiO}_{2}\right)$, hasil XRF dengan kandungan $\mathrm{Si}$ 99,4\% ,hasil analisis sifat mekanis meningkat dengan bertambahnya komposisi nano ASP dan optimal pada komposisi $8 \%$ berat .
\end{abstract}

Kata-kata kunci: $A S P, H D P E$, sifat Mekanis

\begin{abstract}
The purpose of this research is the manufacture nanoparticles of rice husk ash (RHA) that serves as a filler material termopastik poliethylen high density (HDPE). RHA to be prepared rice obtained from refinery combustion products are white. In this research method is performed in the manufacture of nano-particles by means of RHA in Ball mill for 1 hour then synthesized with a solution of $\mathrm{HCl} 2 \mathrm{M}$ $\mathrm{NaOH} 2.5 \mathrm{M}$ by the method of coprecipitation and in the synthesis of polyethylene glycol (PEG) 6000 at a ratio of 1: 3 . the results of this RHA in the characterization namely by means of X-Ray Fluorescent (XRF), morphology analysis by scanning Electron Microscofe (SEM), analysis of the structure of XRay Difraction (XRD), to create nano composite then do the following phases: thermoplastic HDPE included in laboplastomill internal mixer with a temperature of $1500 \mathrm{C}$ at a rate of $60 \mathrm{rpm}$ for 10 minutes, nano RHA with the results of the synthesis of the composition $(0,2,4,6,8$, and 10$) \%$ by weight. From the results of nano composites were analyzed mechanical properties (tensile strength, elongation at break and elastic modulus). The results obtained by XRD $52.22 \mathrm{~nm}$ particle size and crystal structure
\end{abstract}


tetragonal ( $\mathrm{SiO} 2$ )fase cristobalit, XRF results with $99.4 \% \mathrm{Si}$ content, the results of the analysis of the mechanical properties of nano compositions increases with RHA and optimal composition $8 \%$ by weight.

Keywords: $R H A$, HDPE, Mechanical properties

\section{PENDAHULUAN}

Sekam padi merupakan limbah padi yang keberadaannya sangat melimpah di Indonesia namun pemanfaatannya masih terbatas secara tradisional. Sekam padi saat ini telah dikembangkan sebagai bahan baku untuk menghasilkan abu sekam padi yang dikenal di dunia sebagai RHA (Rice Husk Ask). RHA merupakan salah satu bahan baku untuk menghasilkan silika. RHA merupakan salah satu bahan baku silika yang paling kaya mengandung sekitar 90 -98\% silika setelah pembakaran sempurna [1].

Nano silika saat ini telah diaplikasikan dalam berbagai macam bidang diantaranya bidang sains dan industri. ASP telah banyak digunakan sebagai bahan pengisi . Silika telah dimanfaatkan secara luas sebagai katalis, dan berbagai jenis bahan komposit organik-anorganik [2].

Telah banyak dilakukan penelitian tentang pembuatan nano silika dari abu sekam padi dengan cara sintesis antara lain,[1], ukuran partikelnya diperoleh $50 \mathrm{~nm},[3]$,ukuran partikel yang diperoleh $40-200 \mathrm{~nm}$, demikian juga,[4] hasil yang diperoleh rata rata $6 \mathrm{~nm}$.

Bahan alam ini secara umum memiliki sifat hidrofil, maka material tersebut secara umum tidak kompatibel dengan sebagian besar bahan polimer, oleh karena itu secara kimiawi harus dimodifikasi untuk membuat permukaannya yang lebih hidrofobis ,untuk itu diperlukan suatu bahan yang kompatibel dengan matrik polimer.

Penggunaan lapisan silika pada komposit dapat meningkatkan sifat-sifat material (perubahan kapasitas kationik, luas permuakan yang tinggi ,aspek perbandingan yang besar),[5],[6]. Secara esensial dapat meningkatkan sifat fisik dan mekanik ,antara lain kekuatan tarik, modulus tarik , kekuatan lentur, stabilitas panas, sifat termal, untuk beberapa bahan termoplastik dan termoset nanokomposit pada jumlah bahan pengisi silika yang tidak terlalu banyak ,[7],[8],[9].

Tujuan penelitian ini adalah untuk mengetahui ukuran partikel abu sekam padi (ASP) setelah dilakukan preparasi dengan larutan $\mathrm{HCl}$ dan $\mathrm{NaOH}$ dan disintesis dengan polyethelen glycol (PEG)6000 perbandingan 1:3 dilakukan dengan metode kopresitasi, nano partikel yang dihasilkan digunakan sebagai filler pada termoplastik HDPE Serta mengetahui komposisi optimum pencampuran nano partikel ASP pada campuran termoplastik HDPE dengan variasi komposisi nano partikel ASP pada komposisi $(0,2,4,6,8$, dan 10$) \%$ berat.

\section{METODA PENELITIAN}

Bahan

Abu sekam padi (ASP) warna putih dari hasil pembakaran dari kilang padi, $\mathrm{HCl} 2 \mathrm{M}, \mathrm{NaOH}, 2,5$ M (produksi Merck KgaA 64271 Darmstadt Germany ) PEG 6000 ,HDPE produksi PT Titan Petrokimia Nusantara Indonesia

\section{Pengolahan Abu Sekam Padi dengan Metode Kopresipitasi}

Abu sekam padi dalam bentuk serbuk di ball mill selama 1 jam pada kecepatan $250 \mathrm{rpm}$. kemudian diayak menggunakan ayakan 200 mesh. Abu sekam padi yang berukuran $74 \mu \mathrm{m}(200$ mesh) dilarutkan dalam $\mathrm{HCl} 2 \mathrm{M}$ sebanyak $40 \mathrm{ml}$ kemudian diaduk selama 40 menit dengan suhu $70^{\circ} \mathrm{C}$ menggunakan magnetic stirrer. Setelah larutan terbentuk dilakukan penyaringan dengan kertas saring. Selanjutnya dilarutkan menggunakan $\mathrm{NaOH} 2,5 \mathrm{M}$ dan diaduk menggunakan magnetic stirrer. Campuran abu sekam padi dengan larutan $\mathrm{NaOH}$ dipisahkan dengan kertas saring kemudian dicuci dengan aquades dan disaring kembali untuk memisahkan aquades dengan abu sekam padi Kemudian dikeringkan pada oven dengan suhu $70^{\circ} \mathrm{C}$ selama 4 jam. 


\section{Penambahan PEG-6000}

Setelah ASP 10 gram dilarutkan dalam HCL 2 M dan disaring menggunakan kertas saring. Kemudian PEG-6000 yang berbentuk padatan dipanaskan dan dilelehkan dengan suhu $50^{\circ} \mathrm{C}$ selama 15 menit.

PEG-6000 yang sudah mencair ditambahkan ke dalam larutan dengan perbandingan 1:3 kemudian diaduk menggunakan magnetik stirer pada suhu $70^{\circ} \mathrm{C}$ selama 40 menit

Kemudian $\mathrm{NaOH}$ 2,5 M ditambahkan ke dalam campuran PEG-6000 dengan larutan abu sekam padi sambil diaduk menggunakan magnetik stirer.

Selanjutnya larutan tersebut dipisahkan dengan kertas saring dan dicuci dengan mengggunakan aquades dan disaring kembali untuk memisahkan abu sekam padi dengan aquades. Kemudian dikeringkan dalam oven pada suhu $70^{\circ} \mathrm{C}$ selama 2 jam.

\section{Pembuatan Nano Komposit}

Pembuatan Nanokomposit dilakukan dengan mencampurkan termoplastik HDPE dengan Nanopartikel ASP hasil preparasi dengan ukuran 52,22 nm. Pencampuran ini dengan menggunakan alat internal mixer laboplastomil dengan volume chamber $60 \mathrm{cc}$ dengan persentasi pengisian $70 \%$ setara dengan 60 gr. Suhu campuran pada $150^{\circ} \mathrm{C}$ dengan kecepatan rotor $60 \mathrm{rpm}$ selama 10 menit dengan variasi campuran Nano ASP $(0,2,4,6,8,10) \%$ berat terhadap termoplastik HDPE. Hasil nanokomposit dikarakterisasi sifat mekanis, diuji dengan mesin uji tarik stograph R-1 untuk mendapatkan kekuatan tarik maksimum, perpanjangan putus, dan modulus elasitas. Pengujian dilakukan menggunakan standar JIS K 6781.

\section{HASIL DAN PEMBAHASAN}

Dari analisis XRD diperoleh nano partikel ASP dengan Ukuran kristalit sampel dihitung berdasarkan analisis metode Scherrer dari pola difraksi sinar-X.

$$
D=\frac{K \lambda}{B r \operatorname{Cos} \theta}
$$

Dengan $\mathrm{Br}, \mathrm{K}, \lambda$ dan $\mathrm{D}$, berturut-turut adalah lebar setengah puncak full with at half maximum (FWHM) dalam radian, konstanta scherrer $(0,9)$, panjang gelombang sinar-x (1,5406 A), dan diameter kristalit $(\mathrm{nm})$ diperoleh ukuran kristal sebesar 52,22 nm .Pada Gambar 1 dapat dilihat adanya puncak-puncak tertinggi yaitu pada $2 \theta: 20,530^{\circ} ; 21,729^{\circ} ; 23,282^{\circ} ; 27,392^{\circ} ; 30,076^{\circ} ; 36,100^{\circ}$

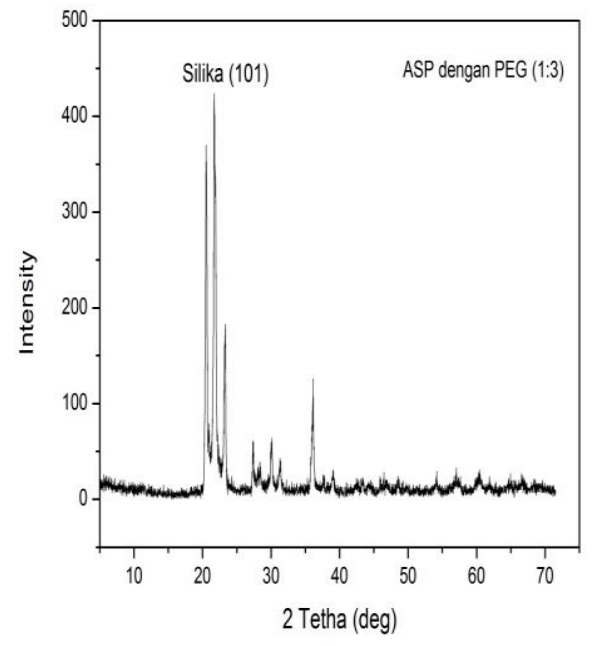

GAMBAR 1. Pola Difraksi Nano Partikel ASP 
Puncak maksimum terdapat pada sudut $2 \theta=21,729^{\circ}$ dengan jarak 4,0867 $\AA$. Hasil pola difraksi sinar-X abu sekam padi dengan PEG-6000 (1:3) memiliki fase kristobalit $\left(\mathrm{SiO}_{2}\right)$ dengan parameter kisi $a=b \neq c$ dengan nilai $a=b=4,9930 \AA c=7,0050 \AA$ sistem kristal tetragonal dan memiliki massa jenis $2,285 \mathrm{~g} / \mathrm{cm}^{\text {al }}$, dimana puncak maksimum Si pada $d_{\mathrm{hkl}}(101)$.Sedangkan hasil penelitian sebelumnya yang dilakukan [10], ASP dengan proses ball mill selama 15 jam diperoleh 53,12 nm. Hasil dari analisa XRF diperoleh kandungan Si 99,4 \% setelah dilakukan preparasi dengan PEG6000 , sebelum preparasi ASP kandungan Si $53 \%$. Gambar 2 menunjukkan morfologi nano partikel ASP.

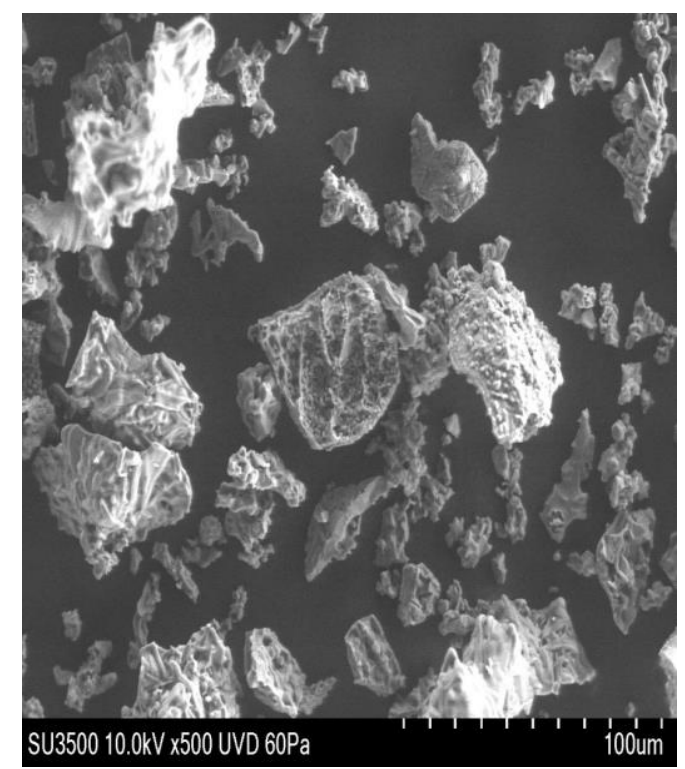

GAMBAR 2. Morfologi Nano partikel ASP

TABEL 1. Sifat Mekanis Nano Komposit

\begin{tabular}{cccccc}
\hline $\begin{array}{c}\text { Material } \\
\text { HDPE//Nano ASP } \\
(\%) \text { berat }\end{array}$ & $\begin{array}{c}\text { Kekuatan } \\
\text { Tarik } \\
(\mathbf{M P a})\end{array}$ & $\begin{array}{c}\text { Modulus } \\
\text { Young's } \\
(\mathbf{M P a})\end{array}$ & $\begin{array}{c}\text { Tegangan } \\
\text { Yield } \\
(\mathbf{M P a})\end{array}$ & $\begin{array}{c}\text { Tegangan } \\
\text { Putus } \\
(\mathbf{M P a})\end{array}$ & $\begin{array}{c}\text { Regangan } \\
\text { Putus } \\
(\% \text { GL) }\end{array}$ \\
\hline 0 & 22.58 & 423.58 & 22.58 & 14.11 & 346.70 \\
2 & 20.81 & 605.76 & 20.80 & 14.13 & 363.83 \\
4 & 20.03 & 587.53 & 20.02 & 14.04 & 425.37 \\
6 & 21.35 & 611.53 & 19.74 & 19.65 & 671.88 \\
8 & 24.79 & 614.54 & 18.95 & 24.66 & 879.28 \\
10 & 23.79 & 642.58 & 19.23 & 22.32 & 803.70 \\
\hline
\end{tabular}




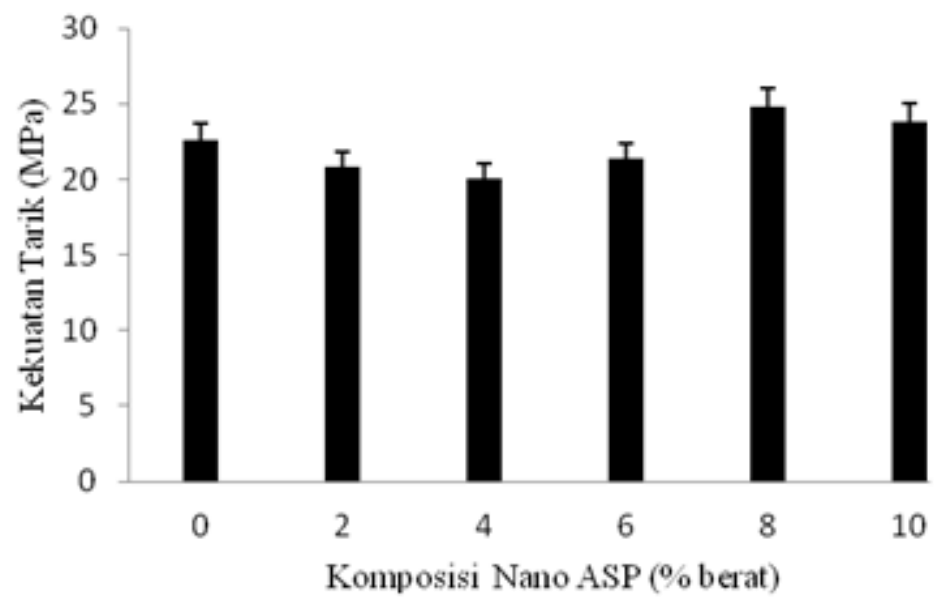

GAMBAR 3 .Hubungan kekuatan Tarik terhadap Komposisi Nano Partikel ASP

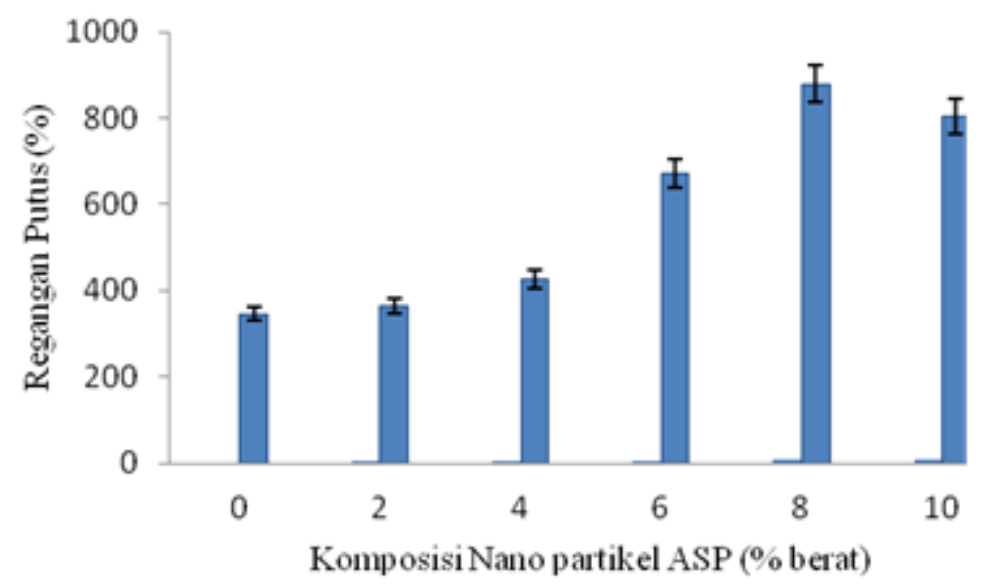

GAMBAR 4 .Hubungan Regangan Terhadap Komposisi Nano Partikel ASP

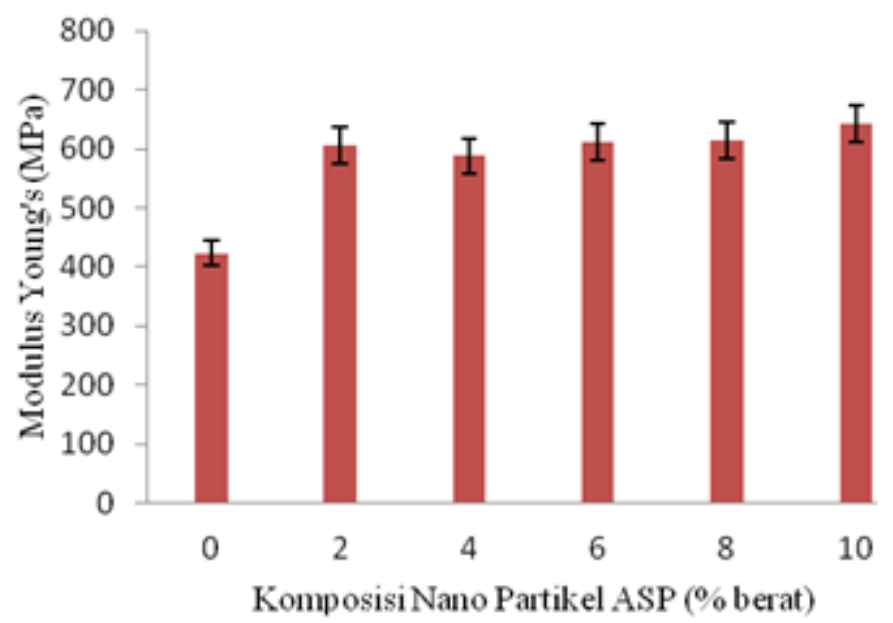

GAMBAR 5 .Hubungan Modulus Young's Terhadap Komposisi Nano Partikel ASP 
Tabel 1 dan Gambar 3 menunjukkan hasil uji tarik untuk masing-masing variasi komposisi nano partikel ASP diperoleh bahwa sampel dengan nilai kekuatan tarik terbesar adalah pada sampel dengan komposisi $8 \%$ kandungan ASP sebesar $24.79 \mathrm{MPa}$, meningkatkan sifat kekuatan tarik nanokomposit disebabkan adanya peningkatan proses pelekatan yang baik antara matrik dengan bahan pengisi yang dapat dilihat dari berkurangnya celah yang timbul dan ukuran partikel yang kecil. dan terjadinya interkalasi antara HDPE dengan nano ASP Sedangkan untuk regangan putus pada Tabel 1 dan Gambar 4 terlihat nilai terbesar adalah komposisi nanopartikel pengisi $8 \%$ berat yakni dengan perpanjangan putus sebesar 879,28 \%. Peningkatan kekuatan ini disebabkan adanya interaksi antara nanokomposit ASP dengan matrik HDPE dikarenakan ukuran partikel yang kecil membuat campuran menjadi homogen dapat meningkatkan kekuatan tarik ,hal ini sesuai dengan penelitian [11-12].

Demikian juga untuk modulus Young's pada Gambar 5 terlihat bahwa dengan penambahan nano partikel ASP modulus Young's meningkat ,hal ini dikarenakan adanya interaksi dan interkalasi antara HDPE dengan nano partikel ASP yang tersebar secara individu memiliki luas kontak permukaan yang besar sehingga dapat berikatan kuat dengan matrik HDPE.

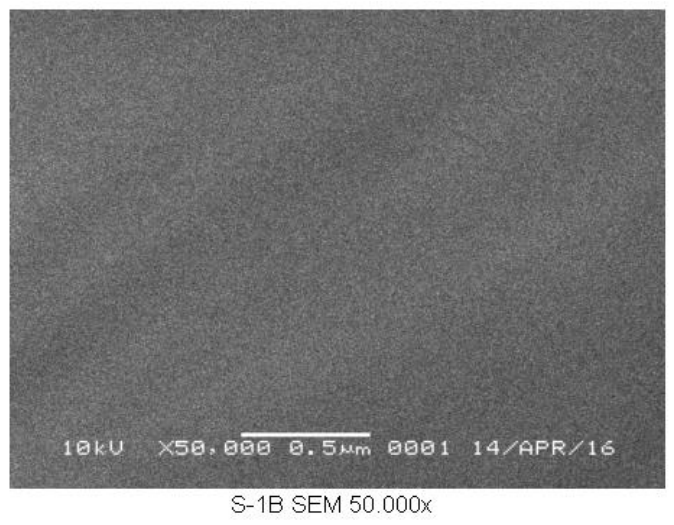

GAMBAR 6. Morfologi Nano Komposit ASP wt 2\%

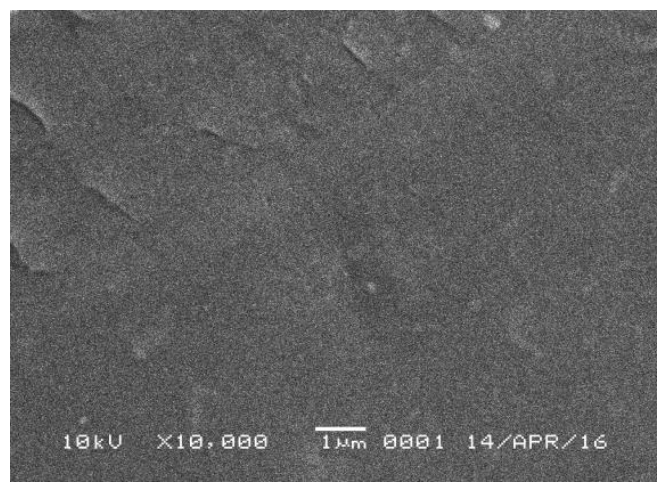

GAMBAR 7. Morfologi Nano Komposit ASP wt 8\%

Gambar 6 dan 7 menujukan campuran nano ASP dengan HDPE masing -masing pada komposisi 2 dan $8 \%$ berat, dari gambar terliahat ke dua campuran homogen sehingga menambah kekuatan tarik dan perpanjangan putus nano komposit .

\section{KESIMPULAN}

Dari hasil XRD diperoleh ukuran kristal sebesar 52,22 nm dengan sistem kristal tetragonal dan fase kristobalit $\mathrm{SiO}_{2}$, sifat mekanis ada peningkatan kekuatan tarik maksimum dengan bertambahnya komposisi nano partikel ASP dibanding dengan HDPE murni, demikian juga halnya dengan perpanjngan putus meningkat dengan bertambahnya komposisi nano partikel ASP dan dari 
hasil morfologi terjadinya dispersi campuran homogen dan interkalasi antara matrik termoplastik HDPE dengan partikel ASP.

\section{UCAPAN TERIMAKASIH}

Peneliti mengucapkan terimakasih pada Kementrian RISTEK DIKTI atas pendanan penelitian ini dalam Hibah penelitian Pundamental tahun 2016 dan labaratorium Fisika Polimer LIPI Bandung atas fasilitas yang diberikan .

\section{DAFTAR ACUAN}

[1] Thuadaij, N and Nuntiya, A., "Synthesis and Characterization of Nanosilica from Rice Husk Ash Prepared by Precipitation Method," CMU.J. Nat. Sci. Special Issue on Nanotechnology, 2008, pp.206-211

[2] Sun, L., Gong, K., "Review, silicon-based materials from rice husks and their applications," Ind. Eng. Chem. Res.40, 2001., pp.5861-5877.

[3] Supakorn Pukird, Pattanasuk Chamninok, Supon Samran, Pristanuch Kasian, Kiattisak Noipa And Lee Chow., "Synthesis and Characterization of $\mathrm{SiO}_{2}$ Nanowires Prepared," Rice Husk Ash , Journal of Metals, Materials and Minerals.19 (2), 2009, pp.33-37

[4] Ezzat Rafiee, Shabnam Shahebrahimi, Mostafa, Feyzi and Mahdi Shaterzadeh, "Optimization of synthesis and characterization of nanosilica," produced from rice husk (a common waste material nternational Nano Letters , 2,2012 , p.29

[5] Tjong,S.C, "structural ang mechanical properties of polymer nanocomposites A.review",Journal of Material Scince and Enginnering.53, 2006,p.73-197.

[6] Utracki,L.A.,Sepehr,M., and Boccaleri, E. "Synthetic layerd nanoparticels for polymeric nanocomposites (PNCs); A review.”Journal of Polymer Advanced Technology . 18, 2007, pp.1-37

[7] Wu,Q.,Lei,y.,Clemons,C.M.,Yao,F.,Xu,Y.,and Lian,K, "Properties of HDPE/Caly/Wood Nanocomposites", Journal of Plastic Technology,2007, 27,pp.108-115

[8] Samal, S. K., Nayak, S., and Mohanty, S. "Polypropylene nanocomposites. Effect of organomodified layered silicates on mechanical, thermal and motphological performance," Journal of Thermoplastic Composite Material. 8, 2008, pp.243-263.

[9] Lei, Y., Wu, Q., Clemons, C. M., Yao. F., and Xu, Y,. "Influence of nanoclay on properties of HDPE/wood composites," Journal of Applied Polymer science. 18, 2007, pp.1425-1433.

[10]Ginting, E. M., Wirjosentono, B., Bukit, N., dan Agusnar, H., "Preparation and Characterization of Rice Husk Ash as Filler Material in to Nanoparticles on Hdpe Thermoplastic Composites, Chemistry and Materials Research” 6 (7), 2014, pp. 14-24

[11]D.Zhang, X.Wang, , L.J . He , W.Song, Z. Sun, B.Han, J.X, Li, "Preparation and characteristic of magnetic $\mathrm{LDPE} / \mathrm{Fe}_{3} \mathrm{O}_{4}$ nano-composite films, Springer Science Business," Media New York 2012, J Mater Sci: Mater Electron , 24 issue 6, 2013, pp.1796-1800

[12]Leblance,J,R.. Rubber-filler "Interaction and Rheology properties in Filled Coumpaund", Prog .Polym Sci .27,2002, pp.627-687 
Spektra: Jurnal Fisika dan Aplikasinya http://doi.org/10.21009/SPEKTRA
Volume 1 Nomor 1,

Agustus 2016
p-ISSN: 2541-3384

e-ISSN: 2541-3392 